\title{
Bowel obstruction caused by colonic metastasis of lung adenocarcinoma: a case report and literature review
}

\author{
N. A. Parker ${ }^{1 *}$ D, C. McBride ${ }^{2}$, J. Forge ${ }^{2}$ and D. Lalich $^{3}$
}

\begin{abstract}
Introduction: Lung cancer is the most common cause of cancer-related deaths globally. Metastatic disease is often found at the time of initial diagnosis in the majority of lung cancer patients. However, colonic metastases are rare. This report describes an uncommon case of colonic metastasis from lung adenocarcinoma.

Case presentation: A 64-year-old female presented to her gastroenterologist for progressively worsening abdominal pain and constipation. Exploratory colonoscopy revealed a large rectosigmoid mass resulting in near total rectal occlusion. Her specialist recommended she immediately go to her regional hospital for further workup. On admission, she complained of continued abdominal pain and constipation. Notably, she had a past medical history of non-small cell lung cancer (T1bN3M0 stage IIIB), diagnosed 1 year prior. She was thought to be in remission following radiation and immunotherapy with pembrolizumab. Upon hospital admission, she underwent an urgent colostomy, ileocecectomy and anastomosis, and rectosigmoid mass resection with tissue sampling. Pathology confirmed the diagnosis of colonic metastasis from primary lung adenocarcinoma. Treatment was with systemic chemotherapy followed by localized radiation to the pelvic region was started. She did not respond well to these therapies. Subsequent imaging showed refractory tumor growth in the pelvic region. Treatment could not be completed due to the patient experiencing a debilitating stroke, and she was transitioned to hospice care.

Conclusions: Clinicians should have a low threshold for intestinal investigation and considerations for colonic metastasis when patients with a history of primary lung cancer have abdominal symptoms.
\end{abstract}

Keywords: Colonic metastasis, Primary lung cancer, Non-small cell lung cancer

\section{Background}

Non-small cell lung carcinoma (NSCLC) accounts for the majority of all lung cancer cases. Metastatic disease is often present at the time of diagnosis, regardless of primary lung cancer type [1-4]. However, colonic metastases are rare. The exact prevalence of large bowel metastasis is difficult to determine. Asymptomatic colonic metastasis has an incidence of approximately $12 \%$ based on autopsy studies [5-10]. Symptomatic colonic metastasis infrequently occurs $[5,6,8,11-14]$. Clinicians should have a high index of suspicion and a low threshold for intestinal tract investigation when primary lung cancer patients present with abdominal symptoms.

\footnotetext{
* Correspondence: nparker6@kumc.edu

${ }^{1}$ Department of Internal Medicine, University of Kansas School of Medicine, 2817 N Tallgrass St, Wichita, KS 67226, USA

Full list of author information is available at the end of the article
}

\section{Case report}

A 64-year-old female was referred to the hospital by her gastroenterologist after a same-day colonoscopy revealed a large rectosigmoid mass resulting in near total rectal occlusion. She had a past medical history of tobacco smoking and NSCLC (T1bN3M0 stage IIIB), diagnosed 1 year prior (Fig. 1). She was thought to be in remission following radiation and immunotherapy with pembrolizumab.

On admission, she complained of progressively worsening abdominal pain and constipation. Vital signs and measurements were unremarkable. Physical examination was primarily benign. Notable laboratory findings only included elevated carcinoembryonic antigen of $4.2 \mathrm{ng} / \mathrm{dL}$. Computerized tomography (CT) imaging showed a severe colonic stool burden and a soft tissue left upper lobe lung mass consistent with patient's NSCLC history. A single large soft tissue mass with possible mucosal invasion in 

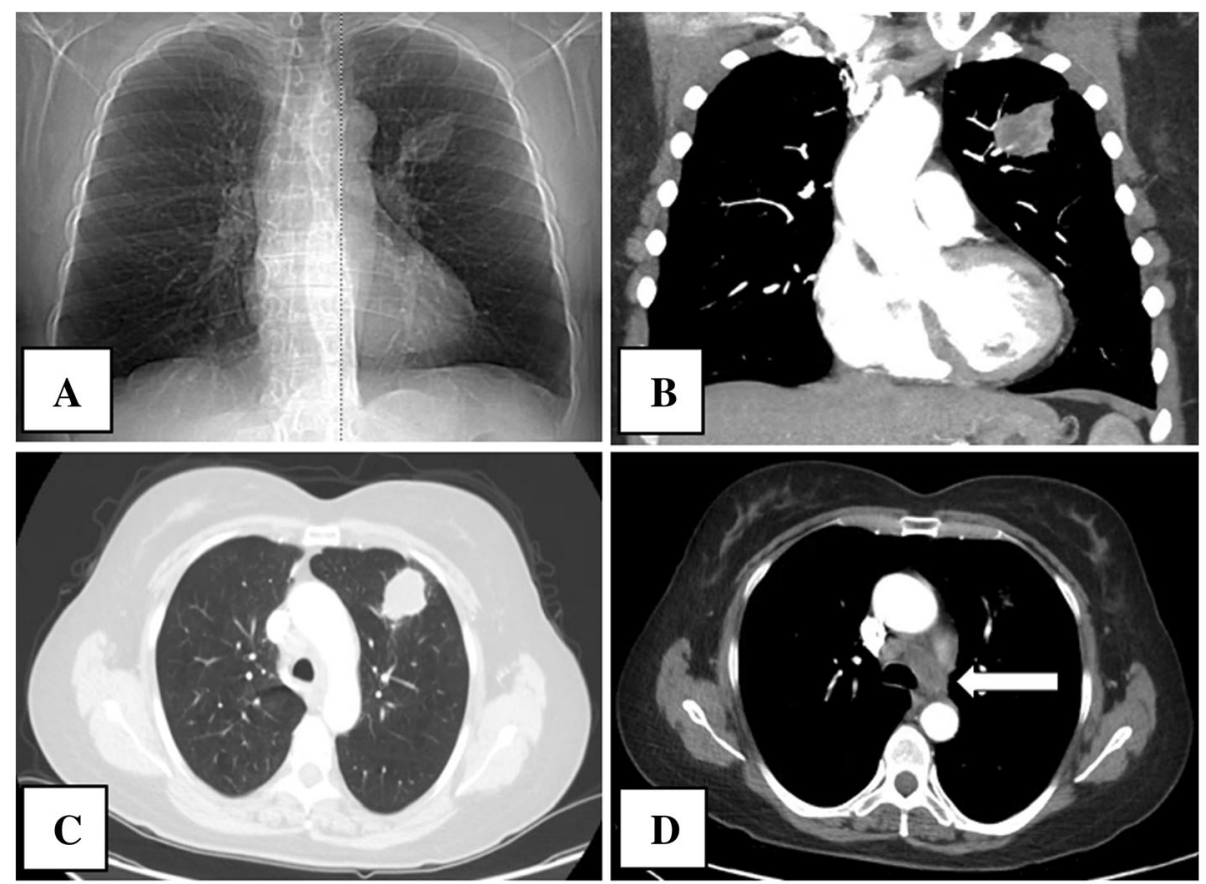

Fig. 1 Chest X-ray and computed tomography showed a tumor in the left lung field. a CXR showed a round mass in the left upper lung field. $\mathbf{b}$ CT coronal image demonstrated the mass anteriorly within the left upper lobe. c CT scan revealed a $3.4 \times 3.1 \mathrm{~cm}$ left upper lobe pulmonary mass lesion most compatible with primary lung cancer. $\mathbf{d}$ CT scan showed abnormal left hilar and mediastinal adenopathy (arrow) suggestive of metastatic nodal involvement

the rectosigmoid colon was noted (Fig. 2). She underwent urgent diagnostic laparoscopy that was quickly converted to open exploratory laparotomy due to numerous bowel-to-bowel and bowel-to-anterior abdominal wall adhesions. At that time, a rectal mass appeared to be invading into the small bowel. Ultimately, colostomy, ileocecectomy and anastomosis, and rectosigmoid mass resection with tissue sampling were performed. She tolerated the procedure well, and her immediate postoperative course was uneventful.
Rectosigmoid mass biopsies revealed positivity for high-grade NSCLC and favored metastatic poorly differentiated adenocarcinoma of lung origin. Hematoxylin and eosin (H\&E) staining showed rectosigmoid mass tissue exhibiting extensive necrosis, focal mucosal involvement, and negativity for regional lymph node carcinoma. Also, normal appearing colonic glandular cells were surrounded by atypical cells infiltrating the colonic stroma. To evaluate these high-grade and poorly differentiated malignant changes further, properly controlled routine
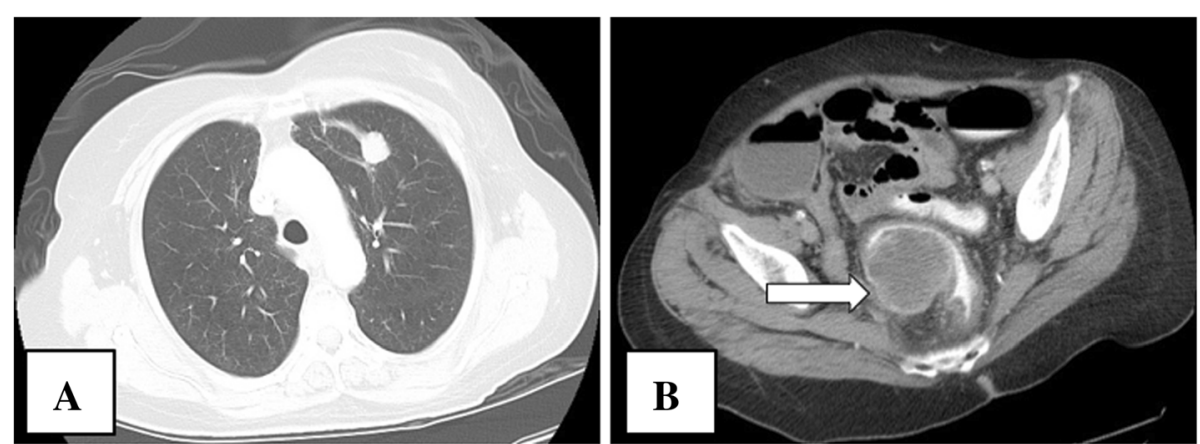

Fig. 2 Imaging showed a tumor in the left lung field and sigmoid colon. a Chest CT revealed a residual soft tissue mass anteriorly within the left upper lobe measuring approximately $2.0 \times 1.7 \mathrm{~cm}$ without appreciable adenopathy (not shown) consistent with the patient's known history of lung cancer. b Abdomen and pelvic CT showed a soft tissue mass with approximate $5.0 \times 4.7 \mathrm{~cm}$ dimensions within sigmoid colon (arrow) at 15 $\mathrm{cm}$ from the anal orifice. A sigmoid mass with extrinsic features and mucosal involvement can be seen contributing to marked narrowing of the sigmoid colon, but allowed contrast to pass through area of narrowing 
immunohistochemical (IHC) stains for cytokeratin 7 (CK7), thyroid transcription factor-1 (TTF-1), Napsin-A, epithelial specific antigen/EpCAM (Moc-31), Ber-EP4, p63, cytokeratin 5 or 6 (CK5, CK6), caudal type homeobox 2 (CDX2), and cytokeratin 20 (CK20) were performed not only based on the patient's age, gender, and past medical history, but also her recent clinical, radiologic, and operative findings. Additional properly controlled IHC stains for leukocyte common antigen (CD45), melanoma antigen recognized by T cells (MART-1), gross cystic disease fluid protein 15 (GCDFP-15), estrogen receptor (ER), synaptophysin, neural-cell adhesion molecule (NCAM/CD56), and chromogranin were performed due to the unusual presentation and nature of the case. The malignant cells exhibited strong positive immunoreactivity for CK7, and positive TTF-1 Napsin-A, Moc-31, and Ber-EP4, while showing only minimal focal staining for p63 and cytokeratin 5 or 6 (CK5, CK6). The tumor was negative for CDX2, CK20, CD45, MART-1, GCDFP-15, ER, synaptophysin, NCAM/CD56, and chromogranin (Fig. 3). Mucicarmine staining was equivocal for intra-cytoplasmic mucin. This IHC staining profile (strongly positive CK7 and positive TTF-1/Napsin-A with negative CDX2/CK20) supported metastatic adenocarcinoma of lung origin, rather than primary colorectal adenocarcinoma. This hypothesis was supported by numerous colonic and regional lymph node samples lacking malignant carcinoma cells and properly controlled IHC stains of right colon and ileum biopsy cells exhibiting negative immunoreactivity for CK7, TTF-1 Napsin-A, Moc-31, and Ber-EP4.

Her postoperative course was uneventful, and she was discharged home. The patient was started on systemic chemotherapy with carboplatin and pemetrexed followed by radiation to the pelvic region for metastatic NSCLC. She did not tolerate chemoradiation therapy well. During the treatment period, she developed considerable pelvic pain resulting in a significant performance status decline. She also experienced multiple prolonged hospitalizations due to infections. Subsequent positron emission tomography-CT (PET-CT) scans suggested refractory pelvic tumor growth. Additional radiation for palliation of pain by reducing pelvic tumor size was determined reasonable. However, the patient experienced a debilitating stroke and was transitioned to hospice care.

\section{Discussion}

The most common NSCLC metastatic site is bone (34\%), followed by lungs (32\%), brain (28\%), adrenal
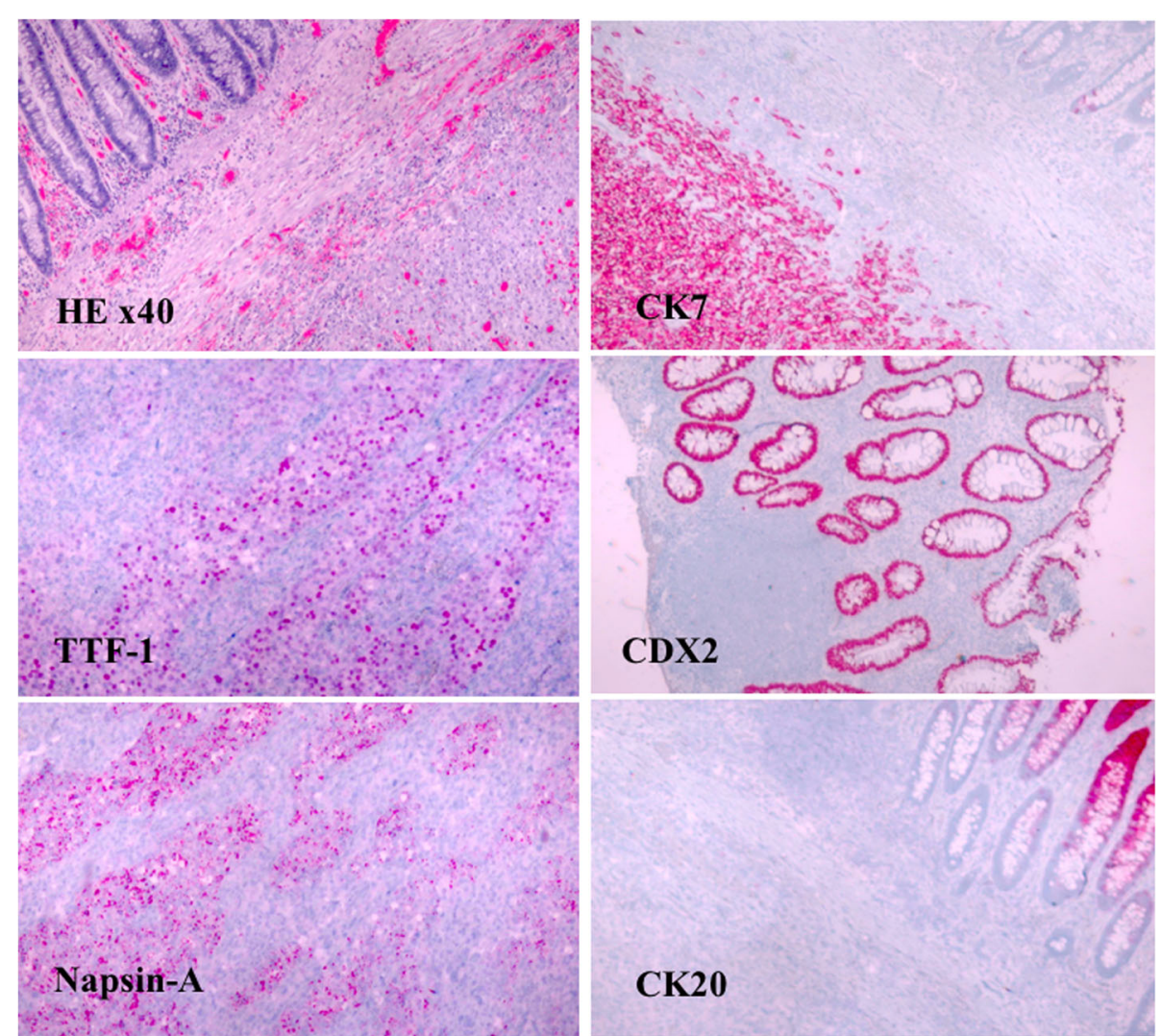

Fig. 3 The pathology specimen demonstrated metastatic lung adenocarcinoma of the colon. (H\&E stain, $\times 40)$. The carcinoma cells were positive for CK7, TTF-1, and Napsin-A, but negative CK20 and CDX2 ( $\times 40)$ 
glands (17\%), liver (13\%), and extrathoracic lymph nodes (9\%) [15]. Colonic metastasis is uncommon with an incidence of $0.1 \%$ [16]. Although metastasis to the colon from lung cancer is uncommon, the phenomenon has been reported [5-56]. Most commonly, the small intestine develops metastatic lesions [5]. This could be due to the enhanced potential of small bowel malignancies to cause serious complications such as perforation, obstruction, or bleeding $[5,6]$. Only 44 unique case reports of lung cancer metastasizing to the colon have been published globally (Table 1 ) $[5,10,13,17-56]$. The pathological diagnosis in 20 of the 44 cases (45\%) was squamous cell carcinoma (SqCC) [13, 17-35]. Twelve lung adenocarcinomas (27\%) and five small cell lung carcinomas (SCC, 11\%) were confirmed as primary origins $[5,10,36-44,46-49,52]$. Large-cell carcinoma of the lung was reported in three cases $(7 \%)[10,50,51]$. Four cases $(9 \%)$ confirmed colonic metastasis from other primary lung histopathologic cell types such as sarcomatoid, pleomorphic, and unknown [53-56]. SqCC had a higher propensity for colonic metastasis [13, 17-35]. Lung adenocarcinoma had the second highest potential for colonic metastasis [10, 36-44, 52]. Abdominal pain due to intestinal tract obstruction was the most frequent initial clinical symptom of metastatic colon cancer from primary malignant lung neoplasms $[19,25,29,32,33$, $37,38,40,43,44,52,53]$. Bloody stool due to either melena or hematochezia was also a common chief complaint $[5,10,17,31,35,48,56]$. Diagnosis of metastatic lung cancer to the colon by incidental polyp discovery occurs infrequently $[10,18,42,55]$. Metastatic colonic neoplasms of lung origin can also present initially with non-bloody diarrhea, encopresis, and hyponatremia [20, 36, 39]. Metastatic lung SqCC and SCC to the colon were associated more with serious complications such as perforation, hemorrhage, and intussusception [13, 22, $47,49,51]$. Lung cancer manifesting as colonic metastasis is rare, and thus cited remotely in case reports. Broad interpretations based on such isolated events should be taken into consideration.

Initial diagnosis of colonic metastasis of lung carcinoma is challenging since its incidence has been reported sporadically. The phenomenon is being reported more frequently due to the recent higher rates of lung cancer in women, increased availability and utilization of endoscopic examinations, and advancements in IHC staining [9]. Details regarding colonic metastasis in terms of typical symptomatology remain sparse. Colonic metastasis of lung carcinoma can present as an incidental polyp, with bloody stool, or by significant bowel obstruction, such as with our patient.

Histological examination, in correlation with clinical findings, remains the gold standard for diagnosis. IHC stains such as TTF-1, CDX2, CK7, and CK20 help
Table 1 Clinical presentations of patients with colonic metastasis, historically (1988-2016)

\begin{tabular}{|c|c|c|}
\hline Case report & Cell type & Symptomatology \\
\hline Azevedo et al. [30] & SqCC & Obstruction \\
\hline Carroll et al. [20] & SqCC & Diarrhea \\
\hline Cedres et al. [29] & $\mathrm{SqCC}$ & Abdominal pain \\
\hline Franco et al. [31] & SqCC & Bloody stool \\
\hline Gateley et al. [22] & $\mathrm{SqCC}$ & Hemorrhage \\
\hline Gitt et al. [13] & SqCC & Perforation \\
\hline Habesoglu et al. [19] & SqCC & Abdominal pain \\
\hline Hirasaki et al. [17] & SqCC & Bloody stool \\
\hline Lou et al. [32] & SqCC & Abdominal pain \\
\hline Ma et al. [33] & $\mathrm{SqCC}$ & Abdominal pain \\
\hline Rouhanimanesh et al. [34] & $\mathrm{SqCC}$ & Obstruction \\
\hline Sakai et al. [25] & $\mathrm{SqCC}$ & Abdominal pain \\
\hline Stinchcombe et al. [18] & SqCC & Incidental polyp \\
\hline Wegener et al. [35] & SqCC & Bloody stool \\
\hline Yuyuan Y. [26] & $\mathrm{SqCC}$ & Obstruction \\
\hline Al-Tarakji et al. [39] & ADC & Encopresis \\
\hline Ceretti et al. [41] & $A D C$ & Obstruction \\
\hline Hsing et al. [40] & $A D C$ & Abdominal pain \\
\hline Huang et al. [37] & ADC & Abdominal pain \\
\hline Miyazaki et al. [38] & ADC & Abdominal pain \\
\hline Ono et al. [52] & $A D C$ & Abdominal pain \\
\hline Pezzuto et al. [36] & ADC & Hyponatremia \\
\hline Pozzato et al. [44] & $A D C$ & Abdominal pain \\
\hline Rossi et al. [10] & ADC, LCC & Polyp, bloody stoo \\
\hline Weng et al. [43] & ADC & Abdominal pain \\
\hline Xue et al. [42] & ADC & Incidental polyp \\
\hline Johnson et al. [48] & SCC & Bloody stool \\
\hline Polak et al. [49] & SCC & Perforation \\
\hline Yang et al. [5] & SCC & Bloody stool \\
\hline Zhidong et al. [47] & SCC & Perforation \\
\hline Goh et al. [51] & LCC & Hemorrhage \\
\hline Chen et al. [53] & $\mathrm{O}$ & Abdominal pain \\
\hline Lin et al. [54] & $\mathrm{O}$ & Intussusception \\
\hline Bastos et al. [56] & $U$ & Bloody stool \\
\hline Myoteri et al. [55] & U & Incidental polyp \\
\hline
\end{tabular}

Particular case reports have been excluded from tabulation due to accessibility and non-English language barriers for symptomatology information only [21, $23,27,28,45,46,50]$

SqCC squamous cell carcinoma, $A D C$ adenocarcinoma, SCC small cell carcinoma, LCC large cell carcinoma, $O$ other: sarcomatoid or pleomorphic, $U$ unknown

distinguish metastatic lung carcinoma from primary colonic cancer $[10,25]$. The immunostaining profile of our patient (strongly positive CK7 and positive TTF-1 with negative CDX2/CK20) supported that her rectosigmoid tumor causing near-total rectal occlusion was metastatic 
adenocarcinoma of lung origin, rather than primary colorectal adenocarcinoma [57-59].

Early detection could be expedited by fecal occult blood testing [56]. This test is generally fast and inexpensive. As a result, stool testing is sufficient in terms of early evaluation and workup, especially in patients with abdominal symptoms and a known history of cancer [17]. PET-CT scans can diagnose asymptomatic colonic metastasis from lung carcinoma $[5,8,18]$. In contrast to conventional CT and endoscopy, PET-CT can determine if an intestinal neoplasm is of primary or secondary tumor origins. However, it is unable to establish an intestinal tumor's specific histopathologic cell type.

Average survivability of patients with primary lung carcinoma, from the time of diagnosis of colonic metastasis to death, varies widely. Moreover, small and large bowel metastasis outcome data are often aggregated. The 5-year survival rate for stage IV metastatic NSCLC is approximately $10 \%$ [60]. Our patient initially received pembrolizumab before the discovery of colonic metastasis. Pembrolizumab is a novel and well-researched cancer immunotherapy most commonly used for tumors that are unresectable, recurrent, or metastatic [61]. Until recently, pembrolizumab has been recommended as a second-line agent. Combination chemotherapy with platinum-based pemetrexed and carboplatin is the first-line treatment for advanced NSCLC [62]. Trends are now focusing on tumor genotype-specific characteristics and in favor of earlier use of immunotherapeutic agents such as pembrolizumab. In a recent open-label phase III trial involving patients with advanced NSCLC, pembrolizumab was associated with significantly longer progression-free and overall survival [61-63]. Also, pembrolizumab was associated with fewer adverse events compared to platinum-based chemotherapy [61-63]. Before our patient's initial presentation with symptomatic rectal occlusion, it was reported she did not tolerate pembrolizumab therapy well due to medication side effects.

All forms of intestinal metastasis of lung carcinoma are considered a late-stage complication of the disease. Average survival following the discovery of colonic metastasis to death has been reported to be approximately 2 months $[5,10,56]$. However, the range of survival after the diagnosis of colonic metastasis from primary lung carcinoma has been found to vary greatly $[5,7-14,17-57]$. Outcomes are based on chief complaints at the time of initial presentation and subsequent surgical intervention $[5,6,11,14,15$, 52, 53]. Perforation, obstruction, or hemorrhage have been associated with less favorable outcomes $[6,11,19,22,48$, $52,53]$. Early detection and surgical intervention have been postulated to improve survival [25]. Furthermore, longer survival times have been observed in patients that underwent palliative surgical resection of the metastatic site $[8,10-25]$, as with our patient.

\section{Conclusion}

Colonic metastasis should be considered when patients have abdominal symptoms and a history of primary lung cancer. Expedited intestinal tract investigation should be done to allow for early detection and treatment. Findings can initially be subtle and isolated, such as a single polyp, bloody stool, or obstruction. Symptoms can be dismissed as a primary gastrointestinal process such as ulcers or colitis. Fecal occult blood testing, PET-CT scans, and endoscopy are clinically useful for establishing a diagnosis. However, histological examination confirms the diagnosis. Many previous case reports of this phenomenon present aggregate data from the small bowel and large bowel metastasis of lung carcinoma. More reports on colonic metastasis of lung carcinoma are required to clarify clinical features and outcomes. Ultimately, early detection and surgical intervention have been thought to improve survival.

\section{Abbreviations \\ CD45: Leukocyte common antigen; CDX2: Caudal type homeobox 2; CK20: Cytokeratin 20; CK5/6: Cytokeratin 5 or 6; CK7: Cytokeratin 7; \\ $\mathrm{CT}$ : Computerized tomography; ER: Estrogen receptor; GCDFP-15: Gross cystic disease fluid protein 15; H\&E: Hemotoxylin and eosin; \\ IHC: Immunohistochemical; MART-1: Melanoma antigen recognized by T cells; Moc-31: Epithelial specific antigen/EpCAM; NCAM/CD56: Neural-cell adhesion molecule; NSCLC: Non-small cell lung carcinoma; PD- \\ L1: Programmed death-ligand 1; PET-CT: Positron emission tomography-CT; \\ SqCC: Squamous cell carcinoma; TTF-1: Thyroid transcription factor-1}

\section{Acknowledgements}

Not applicable.

Funding

Not applicable.

Availability of data and materials

The material supporting the conclusion of this review has been included within the article.

\section{Authors' contributions}

NP performed data collection and wrote manuscript. DL facilitated in pathology image access and interpretation. CM, JF, and DL participated in the editing of the manuscript. All authors have read and approved of the manuscript.

Ethics approval and consent to participate

The data collection on the patient had been approved by the local Ethical committee.

\section{Consent for publication}

Written informed consent for publication of their clinical details and/or clinical images was obtained from the patient/parent/guardian/ relative of the patient.

Competing interests

The authors declare that they have no competing interests.

\section{Publisher's Note}

Springer Nature remains neutral with regard to jurisdictional claims in published maps and institutional affiliations.

\section{Author details}

${ }^{1}$ Department of Internal Medicine, University of Kansas School of Medicine, 2817 N Tallgrass St, Wichita, KS 67226, USA. Department of Internal Medicine, University of Kansas School of Medicine, 1010 N Kansas St, Wichita, KS 67214, USA. ${ }^{3}$ Department of Anatomical and Clinical Pathology, Wesley Medical Center, 550 N. Hillside St, Wichita, KS 67214, USA. 
Received: 20 January 2019 Accepted: 29 March 2019 Published online: 08 April 2019

\section{References}

1. Goldstraw P, Crowley J, Chansky K, Giroux D, Groome P, Rami-Porta R, Postmus P, Rusch V, Sobin L. The IASLC Lung Cancer Staging Project: proposals for the revision of the TNM stage groupings in the forthcoming (seventh) edition of the TNM classification of malignant tumours. J Thorac Oncol. 2007;2(8):706-14.

2. Siegel R, Naishadham D, Jemal A. Cancer statistics, 2012. CA Cancer J Clin. 2012;62(1):10-29.

3. Hori M, Matsuda T, Shibata A, Katanoda K, Sobue T, Nishimoto H. Cancer incidence and incidence rates in Japan in 2009: a study of 32 populationbased cancer registries for the Monitoring of Cancer Incidence in Japan (MCIJ) project. Jpn J Clin Oncol. 2015;45(9):884-91.

4. Little AG, Gay EG, Gaspar LE, Stewart AK. National survey of non-small cell lung cancer in the United States: Epidemiology, pathology and patterns of care. Lung Cancer. 2007:57(3):253-60.

5. Yang CJ, Hwang JJ, Kang WY, et al. Gastro-intestinal metastasis of primary lung carcinoma: clinical presentations and outcome. Lung Cancer. 2006;54 319-23.

6. Hu Y, Feit N, Huang Y, Xu W, Zheng S, Li X. Gastrointestinal metastasis of primary lung cancer: An analysis of 366 cases. Oncol Lett. 2018;15(6):9766-76.

7. Yoshimoto A, Kasahara K, Kawashima A. Gastrointestinal metastases from primary lung cancer. Eur J Cancer. 2006;42(18):3157-60.

8. Kim MS, Kook EH, Ahn SH, et al. Gastrointestinal metastasis of lung cancer with special emphasis on a long-term survivor after operation. J Cancer Res Clin Oncol. 2009:135(2):297-301.

9. McNeill PM, Wagman LD, Neifeld JP. Small bowel metastases from primary carcinoma of the lung. Cancer. 1987;59:1486-9.

10. Rossi G, Marchioni A, Romagnani E, Bertolini F, Longo L, Cavazza A, Barbieri F. Primary lung cancer presenting with gastrointestinal tract involvement: clinicopathologic and immunohistochemical features in a series of 18 consecutive cases. J Thorac Oncol. 2007;2(2):115-20.

11. Berger A, Cellier C, Daniel C, Kron C, Riquet M, Barbier JP, Cugnenc PH, Landi B. Small bowel metastases from primary carcinoma of the lung: clinical findings and outcome. Am J Gastroenterol. 1999;94:1884-7.

12. Kim SY, Ha HK, Park SW, Kang J, Kim KW, Lee SS, Park SH, Kim AY. Gastrointestinal metastasis from primary lung cancer: $C T$ findings and clinicopathologic features. AJR Am J Roentgenol. 2009;193(3):W197-201.

13. Gitt SM, Flint P, Fredell CH, Schmitz GL. Bowel perforation due to metastatic lung cancer. J Surg Oncol. 1992;51:287-91.

14. Lee PC, Lo C, Lin MT, Liang JT, Lin BR. Role of surgical intervention in managing gastrointestinal metastases from lung cancer. World J Gastroenterol. 2011;17(38):4314-20.

15. Hillers TK, Sauve MD, Guyatt GH. Analysis of published studies on the detection of extrathoracic metastases in patients presumed to have operable non-small cell lung cancer. Thorax. 1994:49:14-9.

16. Tamura T, Kurishima K, Nakazawa K, Kagohashi K, Ishikawa H, Satoh H. Specific organ metastases and survival in metastatic non-small-cell lung cancer. Mol Clin Oncol. 2015;3(1):217-21.

17. Hirasaki S, Suzuki S, Umemura S, Kamei H, Okuda M, Kudo K. Asymptomatic colonic metastases from primary squamous cell carcinoma of the lung with a positive fecal occult blood test. World J Gastroenterol. 2008;14(35):5481-3.

18. Stinchcombe TE, Socinski MA, Gangarosa LM, Khandani AH. Lung cancer presenting with a solitary colon metastasis detected on positron emission tomography scan. J Clin Oncol. 2006;24(30):4939-40.

19. Habesoglu MA, Oguzulgen Kl, Ozturk C, Akyurek N, Memis L. A case of bronchogenic carcinoma presenting with acute abdomen. Tuberk Toraks. 2005;53(3):280-3.

20. Carroll D, Rajesh PB. Colonic metastases from primary squamous cel carcinoma of the lung. Eur J Cardiothorac Surg. 2001;19(5):719-20.

21. Joffe N. Symptomatic gastrointestinal metastases secondary to bronchogenic carcinoma. Clin Radiol. 1978;29(2):217-25.

22. Gateley CA, Lewis WG, Sturdy DE. Massive lower gastrointestinal hemorrhage secondary to metastatic squamous cell carcinoma of the lung. Br J Clin Pract. 1993:47:276-7.

23. Brown KL, Beg RA, Demany MA, Lacerna MA. Rare metastasis of primary bronchogenic carcinoma to sigmoid colon: report of a case. Dis Colon Rectum. 1980;23(5):343-5.
24. Smith HJ, Vlasak MG. Metastasis to the colon from bronchogenic carcinoma. Gastrointest Radiol. 1978;2(4):393-6.

25. Sakai $\mathrm{H}$, Egi $\mathrm{H}$, Hinoi $\mathrm{T}$, et al. Primary lung cancer presenting with metastasis to the colon: a case report. World J Surg Oncol. 2012;10:127.

26. Yuyuan Y. Bowel obstruction caused by colonic metastasis of squamous cell lung cancer: a case report. Chin J Cancer. 1999;18:143.

27. Wu W, Mu J, Tong L, Liu Z. Primary lung squamous cell carcinoma ileocecal metastasis: one case report and literature review. Int J Respir. 2011;31:1225-7.

28. Xiangtao M, Liwei Y, Jing F, Shan W, Ruyi D, Zhirong C. Colonic metastasis of squamous cell lung cancer: a case report and review. Cancer Res Prev Treat. 2006;33:631

29. Cedres S, Mulet-Margalef N, Montero MA, Martinez P, Martinez A, Felip E. Rectal metastases from squamous cell carcinoma: a case report and review of the literature. Case Rep Med. 2012;2012:947524.

30. Azevedo CR, Cezana L, Moraes ES, Begnami MD, Junior Paiva TF, Dettino AL, Fanelli MF. Synchronous thyroid and colon metastases from epidermoid carcinoma of the lung: case report. Sao Paulo Med J. 2010;128:371-4.

31. Franco I, et al. Single symptomatic colonic metastasis as first presentation of a pulmonary mucoepidermoid carcinoma. Clin Respir J. 2016;10(4):524-9.

32. Lou HZ, et al. Colonic metastasis after resection of primary squamous cell carcinoma of the lung: a case report and literature review. World J Gastroenterol. 2014;20(19):5930-4.

33. Ma XT, Yu LW, Fu J. Paraneoplastic syndromes of hypercalcemia and leukocytosis associated with colonic metastases from squamous cell carcinoma of the lung. Int J Color Dis. 2008;23(1):129-30.

34. Rouhanimanesh $Y$, Vanderstighelen $Y$, Vanderputte $S$, Cools $P$, Wassenaar $H$, Vallaeys J. Intra-abdominal metastases from primary carcinoma of the lung. Acta Chir Belg. 2001;101(6):300-3.

35. Wegener M, Borsch G, Reitemeyer E, Schafer K. Metastasis to the colon from primary bronchogenic carcinoma presenting as occult gastrointestinal bleeding - report of a case. Gastroenterol. 1988;26(7):358-62.

36. Pezzuto A, Mariotta S, Fioretti F, Uccini S. Metastasis to the colon from lung cancer presenting with severe hyponatremia and dyspnea in a young male: A case report and review of the literature. Oncol Lett. 2013:5:1477-80.

37. Huang YM, Hsieh TY, Chen JR, Chien HP, Chang PH, Wang CH, Huang JS. Gastric and colonic metastases from primary lung adenocarcinoma: A case report and review of the literature. Oncol Lett. 2012;4:517-20.

38. Miyazaki K, Satoh H, Sekizawa K. Metastasis to appendix from lung adenocarcinoma. Int J Gastrointest Cancer. 2005;36:59-60.

39. Al-Tarakji M, et al. Rare occurrence of metastasis from lung cancer to the anus: case report and review of the literature. World J Surg Oncol. 2016; 14(157).

40. Hsing $C T$, et al. Gastrointestinal metastasis from a primary adenocarcinoma of the lung presenting with acute abdominal pain. Korean J Gastroenterol. 2012:59(5):382-5.

41. Ceretti AP, Goi G, Barabino M, De Nicola E, Strada D, Bislenghi G, Opocher E. Colonic metastasis from primary carcinoma of the lung. Case report. Ann Ital Chir. 2011:82:229-32

42. $\mathrm{Xue} X \mathrm{XY}$, et al. Colonic metastasis from primary lung adenocarcinoma: case report and review of the literature. Med Oncol. 2012;29(2):644-7.

43. Weng MW, Wang HC, Chiou JC, Lin SL, Lai RS. Colonic metastasis from a primary adenocarcinoma of the lung presenting with acute abdominal pain: a case report. Kaohsiung J Med Sci. 2010;26(1):40-4.

44. Pozzato P, Salerno A, Cancellieri A, Ventrucci M. Colonic metastasis from a primary adenocarcinoma of the lung presenting with acute abdominal pain. Dig Liver Dis. 2012;44(6)

45. Ahn SE, Lee HL, Lee OY, Yoon BC, Choi HS, Hahm JS, Park SW, et al. Colonic metastasis from primary lung adenocarcinoma. Korean J Gastroenterol. 2009;53(2):121-5.

46. Jianguo S, Xiufeng Z, Qingmei J. A case report of rectal metastasis of small cell lung cancer. Chin J Cancer Prev Treat. 2000;7:369.

47. Zhidong L, Weijun Z, Funan L, Yimin D, Jixian S. Bowel perforation caused by colonic metastasis of small cell lung cancer: a case report. J Basic Clin Oncol. 2010:23:451-2.

48. Johnson AO, Allen MB. Rectal metastases from small cell lung cancer. Respir Med. 1995:89(3):223-5

49. Polak M, Kupryjanczyk J, Rell KW. A rare case of colonic perforation in a sole site of latent lung cancer metastasis. Pol Tyg Lek. 1990;45(8-9):179-81.

50. Xiangtao $M$, Liwei $Y$, Jing $F$, Shan W, Ruyi D, Zhirong C. A case report of colonic metastasis of undifferentiated lung cancer. Chin J Clin Oncol. 2006; $33: 358$. 
51. Goh BK, Yeo AW, Koong HN, Ooi LL, Wong WK. Laparotomy for acute complications of gastrointestinal metastases from lung cancer: is it a worthwhile or futile effort? Surg Today. 2007;37(5):370-4.

52. Ono H, Okabe M, Kimura T, Kawakami M, Nakamura K, Danjo Y, Takasugi H, Nishihara $\mathrm{H}$. Colonic metastasis from primary carcinoma of the lung: Report of a case and review of Japanese literature. Clin J Gastroenterol. 2009;2:89-95.

53. Chen $\mathrm{CH}$, et al. Gastrointestinal metastasis from primary sarcomatoid carcinoma of the lung: a case report and review of the literature. World J Surg Oncol. 2015;13:174.

54. Lin MW, Wu CT, Chang YL. Intussusception caused by intestinal metastasis from lung pleomorphic carcinoma. Ann Thorac Cardiovasc Surg. 2014: 20(Suppl):635-8.

55. Myoteri D, Dellaportas D, Zizi-Sermpetzoglou A. Colonic polyp harboring lung cancer metastasis: an unpleasant surprise. J BUON. 2015;20(3):933.

56. Bastos I, Gomes D, Gouveia H, de Freitas D. Colonic metastasis of a lung carcinoma with ileocolic fistula. J Clin Gastroenterol. 1998;26:348.

57. Saad RS, Ghorab Z, Khalifa MA, Xu M. CDX2 as a marker for intestinal differentiation: its utility and limitations. World I Gastrointest Surg. 2011; 3(11):159-66.

58. Hinoi T, Tani M, Lucas PC, Caca K, Dunn RL, Macri E, Loda M, Appelman HD, Cho KR, Fearon ER. Loss of CDX2 expression and microsatellite instability are prominent features of large cell minimally differentiated carcinomas of the colon. Am J Pathol. 2001;159(6):2239-48.

59. Shin JH, Bae JH, Lee A, Jung CK, Yim HW, Park JS, Lee KY. CK7, CK20, CDX2 and MUC2 immunohistochemical staining used to distinguish metastatic colorectal carcinoma involving ovary from primary ovarian mucinous adenocarcinoma. Jpn J Clin Oncol. 2010;40(3):208-13.

60. Lung cancer - non-small cell: statistics [Internet]. Cancer.Net. Cancer.Net Editorial Board; 2018 [cited 2018Nov2]. Available from: https:/www.cancer. net/cancer-types/lung-cancer-non-small-cell/statistics.

61. Ettinger DS, Wood DE, Aisner DL, et al. Non-small cell lung cancer, version 5.2017, NCCN clinical practice guidelines in oncology. J Natl Compr Cancer Netw. 2017;15(4):504-35.

62. Reck M, Rodriguez-Abreu D, Robinson AG. Pembrolizumab versus chemotherapy for PD-L1-positive non-small-cell lung cancer. N Engl J Med. 2016;375:1823-33.

63. Garon EB, Rizvi NA, Hui R, et al. Pembrolizumab for the treatment of nonsmall-cell lung cancer. N Engl J Med. 2015;372:2018-28.

Ready to submit your research? Choose BMC and benefit from:

- fast, convenient online submission

- thorough peer review by experienced researchers in your field

- rapid publication on acceptance

- support for research data, including large and complex data types

- gold Open Access which fosters wider collaboration and increased citations

- maximum visibility for your research: over $100 \mathrm{M}$ website views per year

At $\mathrm{BMC}$, research is always in progress.

Learn more biomedcentral.com/submissions 